Tomoya Asaka • Ken Ikeuchi • Soichi Okino

Yasuki Takizawa $\cdot$ Ryozo Satake $\cdot$ Eishun Nitta

Kiyonobu Komai • Koutaro Endo • Sari Higuchi

Takuo Oyake · Toshiro Yoshimura • Akihito Suenaga

Eiichiro Uyama • Toyokazu Saito • Masaaki Konagaya

Nobuhiko Sunohara $\cdot$ Reiko Namba $\cdot$ Hiroshi Takada

Kazuya Honke • Makiko Nishina • Hajime Tanaka

Mariko Shinagawa $\cdot$ Keiko Tanaka $\cdot$ Akihiro Matsushima

Shoji Tsuji • Masaharu Takamori

\title{
Homozygosity and linkage disequilibrium mapping of autosomal recessive distal myopathy (Nonaka distal myopathy)
}

Received: January 18, 2001 / Accepted: August 21, 2001

\begin{abstract}
Autosomal recessive distal myopathy or Nonaka distal myopathy (NM) is characterized by its unique distribution of muscular weakness and wasting. The patients present with spared quadriceps muscles even in a late stage of the disease. The hamstring and tibialis anterior muscles are affected severely in early adulthood. We have localized the $N M$ gene to the region between markers D9S319 and D9S276 on chromosome 9 by linkage analysis. To further refine the localization of the $N M$ gene, we conducted homozygosity and linkage disequilibrium analysis for 14 patients from $11 \mathrm{NM}$ families using 18 polymorphic markers. All of the patients from consanguineous NM families were found to be homozygous for six markers located within the region between markers D9S2178 and D9S1859. We also provided evidence for significant allelic associations between the $N M$ region and five marker loci. Examination of the haplotype analysis identified a predominant ancestral haplotype comprising the associated alleles 199-160-154109 (marker order: D9S2179-D9S2180-D9S2181-D9S1804), present in $60 \%$ of $N M$ chromosomes and in $0 \%$ of parent
\end{abstract}

T. Asaka ${ }^{1}(\bowtie) \cdot$ S. Okino $\cdot$ Y. Takizawa $\cdot$ R. Satake $\cdot$ E. Nitta

K. Komai $\cdot$ M. Takamori

Department of Neurology, Kanazawa University School of Medicine,

13-1 Takaramachi, Kanazawa 920-8640, Japan

K. Ikeuchi $\cdot$ K. Endo $\cdot$ S. Higuchi $\cdot$ T. Oyake $\cdot$ H. Tanaka $\cdot$

K. Tanaka $\cdot$ S. Tsuji

Department of Neurology, Brain Research Institute, Niigata

University, Niigata, Japan

T. Yoshimura $\cdot$ A. Suenaga

Department of Internal Medicine, Nagasaki University School of Medicine, Nagasaki, Japan

E. Uyama

Department of Neurology, Kumamoto University School of

Medicine, Kumamoto, Japan

T. Saito

Department of Neurology, Kitazato University School of Medicine,

Sagamihara, Japan

M. Konagaya

Department of Neurology, National Suzuka Hospital, Suzuka, Japan chromosomes. On the basis of the data obtained in this study, the majority of $N M$ chromosomes were derived from a single ancestral founder, and the $N M$ gene is probably located within the $1.5-\mathrm{Mb}$ region between markers D9S2178 and D9S1791.

Key words Quadriceps-sparing myopathy $\cdot$ Hereditary inclusion body myopathy - Distal myopathy with rimmed vacuole formation $\cdot$ Ancestral haplotype $\cdot$ Founder

\section{Introduction}

Autosomal recessive distal myopathy is a slowly progressive muscular disorder known as Nonaka distal myopathy (NM) in Japan (Nonaka et al. 1981). The profile of NM includes muscular weakness and wasting, which is prominent in the tibialis anterior and hamstring muscle in early adulthood. The spared quadriceps muscle even in late adulthood is a

N. Sunohara

Department of Neurology, National Center of Neurology and Psychiatry, Tokyo, Japan

R. Namba $\cdot$ H. Takada

Department of Neurology, National Okayama Minami Hospital,

Okayama, Japan

K. Honke

Department of Pediatrics, National Iou Hospital, Kanazawa, Japan

M. Nishina

Department of Internal Medicine, Toho University School of Medicine, Tokyo, Japan

M. Shinagawa $\cdot$ A. Matsushima

National Nanao Hospital, Nanao, Japan

Present address:

${ }^{1}$ Department of Laboratory Medicine (Molecular Genetics) and Neurology, National Nanao Hospital, 8-3-1 Mattou-machi, Nanao 926-0841, Japan

Tel. +81-767-53-1890; Fax +81-767-53-5771

e-mail tomoya@nanao.hosp.go.jp

The first two authors contributed equally to this work 
unique feature of this myopathy. The muscle biopsy specimen discloses a vacuolar myopathy without inflammation (Matsubara and Tanabe 1982; Nonaka and Engel 1985, 1998; Nonaka 1999; Mizusawa et al. 1987; Sunohara et al. 1989; Barohn et al. 1998; Illa 2000).

These clinical and pathological characteristics are strikingly similar to those of hereditary inclusion body myopathy (hIBM or quadriceps-sparing myopathy)(Argov and Yarom 1984). Askanas and Engel (1995) suspected that these myopathies were the same entity. Thus far, the molecular background of these myopathies remains elusive, although several research groups have performed genetic and linkage analysis on these myopathies as well as on other types of distal myopathies (Laing et al. 1995; Ahlberg et al. 1998a, b; Haravuori et al. 1998).

Murakami et al. (1995) and Askanas and Engel (1995, 1998) showed that muscle fibers of patients with NM and hIBM show accumulation of beta-Amyloid protein, as do the brains of patients with Alzheimer disease. Mutations in exons 16 and 17 of the beta-amyloid precursor protein $(\beta \mathrm{APP})$ gene on chromosome 21 were identified in patients with early onset familial Alzheimer disease (Mullan et al. 1992; Levy et al. 1990). Sivakumar et al. (1995) investigated the presence of similar mutations in exon 16 and exon 17 of $\beta A P P$ in patients with hIBM by direct sequencing. However, no mutation was observed in either exon, and they speculated that accumulation of $\beta$ APP was an epiphenomenon unrelated to the pathogenesis of hIBM.

By applying linkage analysis, Mitrani-Rosenbaum et al. (1996) mapped the disease locus responsible for hIBM in Persian-Jewish families to chromosome 9p1-9q1. Extended work by Argov et al. (1997) demonstrated that the gene for hIBM with spared quadriceps was linked to chromosome 9p1-9q1 in families of Afghani Jews, Iraqi Jews, and non-Jews originating from India. By contrast, no linkage was shown between the disease locus and chromosome 9 in a French-Canadian hIBM family in which affected individuals showed white-matter involvement. The results suggested that hIBM encompasses several syndromes (Askanas and Engel 1995).

Ikeuchi et al. (1997) also used linkage analysis to localize the $N M$ gene to a $23.3-\mathrm{cM}$ interval defined by polymorphic markers D9S319 and D9S276 on chromosome 9. Interestingly, the candidate region for the $N M$ and $h I B M$ genes overlapped in a 15-cM interval between markers D9S165 and D9S276, indicating that both disorders might result from allelic mutation of the same gene (Askanas 1997).

In a previous study by Ikeuchi et al. (1997), no linkage disequilibrium was found between the $N M$ region and marker loci. If linkage disequilibrium between the disease locus and marker loci can be detected, a powerful approach by which to narrow the critical region toward which positional cloning efforts should be directed will be available. Here we describe homozygosity and linkage disequilibrium mapping in order to greatly refine the assignment of the $N M$ gene by using newly developed polymorphic markers, and we present the evidence for linkage disequilibrium between the $N M$ region and several marker loci.

\section{Subjects and methods}

\section{Patients and families}

Linkage has been shown between the disease locus and chromosome 9 in 2 of 11 families (families 6 and 7) (Ikeuchi et al. 1997). The other 9 families who permitted analysis of DNA samples were not previously reported. Thus, 11 pedigrees with $14 \mathrm{NM}$ patients and 25 unaffected family members (17 parents and 8 siblings) were included in this study. All of the families were Japanese, and consanguinity was present in 6 of 11 families. The clinical history of living members was ascertained through interviews, examinations, and medical records. The affection status of deceased members was determined from medical records or reports from other family members.

Clinical diagnosis of NM was established by at least one neurologist based on clinical course, family history, and neurological examinations, giving special attention to the presentation of the predominantly affected tibialis anterior muscle and the spared quadriceps muscle. Affection status was confirmed by the presence of the characteristic inclusion bodies in a muscle biopsy specimen. Unaffected individuals in this study had been evaluated by at least one neurologist.

One symptomatic patient (family 1-6) whose muscle biopsy specimen lacked typical inclusion bodies was considered to have NM on the basis of the presence of typical clinical symptoms and the fact that a clinically symptomatic sibling showed characteristic inclusion bodies in his muscle biopsy specimen. Except for this patient, the biopsied specimens of all affected subjects showed typical inclusion bodies.

Another symptomatic patient (family 4-4), in whom onset occurred at age 15 , showed relatively rapid progression of muscle atrophy. This subject was included in this study because clinical and pathological studies confirmed that he had NM.

\section{Genomic DNA preparation}

Twenty milliliters of anticoagulated venous blood was collected from each participating living family member after informed consent had been obtained. Red blood cells were lysed by use of hypotonic osmotic shock for $1 \mathrm{~min}$. Lymphocytes were harvested and then digested with sodium dodecyl sulfate and proteinase $\mathrm{K}$ overnight at $37^{\circ} \mathrm{C}$. Subsequently, standard phenol/chloroform extraction followed by ethanol precipitation was used to prepare genomic DNA.

\section{Development of new microsatellite markers}

New polymorphic DNA markers including dinucleotide and tetranucleotide repeats were searched for in the human genome sequence database (http://www.ncbi.nlm.nih.gov/). After the primer sets were designed, variations in dinucleotide- and tetranucleotide-repeat numbers were examined 
by polymerase chain reaction (PCR) amplification of the genomic DNA of 44 unrelated Japanese individuals. Highly polymorphic markers were then selected for homozygosity mapping and linkage disequilibrium analysis.

\section{Genotyping}

Eighteen polymorphic microsatellite markers, which map the region between markers D9S1678 and D9S273 and cover an estimated region of $15 \mathrm{cM}$ on chromosome $9 \mathrm{p} 1$, were used to narrow the $N M$ region. Nine primer sequences for the markers used have been published (Dib et al. 1996). The additional markers were newly generated in this study, and five important primer sequences are described in Table 1. Genotyping was performed by use of 6-FAM (Applied Biosystems, Tokyo, Japan) labeled primers and an ABI 310 Genetic Analyzer (Applied Biosystems) equipped with GeneScan software (Applied Biosystems).

PCR amplification was performed in a final volume of $12.5 \mu \mathrm{l}$ containing of $10 \mathrm{ng}$ of genomic DNA, $2.5 \mu \mathrm{mol}$ of each primer, 0.75 units of Taq polymerase (Takara, Tokyo, Japan), $200 \mu \mathrm{mol}$ each of deoxyribonucleotide triphosphate, and reaction buffer provided by the company (Takara). After denaturation at $95^{\circ} \mathrm{C}$ for $5 \mathrm{~min}$, samples were subjected to 30 cycles of $30 \mathrm{~s}$ each at $95^{\circ} \mathrm{C}$ for denaturing, $30 \mathrm{~s}$ at the optimum annealing temperature, and $3 \mathrm{~min}$ at $72^{\circ} \mathrm{C}$ for extension, followed by a final extension at $72^{\circ} \mathrm{C}$ for $7 \mathrm{~min}$.

After amplification, $0.5 \mu \mathrm{l}$ of the reaction mixture was mixed with $10 \mu \mathrm{l}$ of deionized formamide (Amresco, Solon, $\mathrm{OH}, \mathrm{USA}$ ) and $0.5 \mu \mathrm{l}$ of the TAMRA-labeled molecular marker (GeneScan 500, Applied Biosystems). The mixed samples were denatured at $95^{\circ} \mathrm{C}$ for $10 \mathrm{~min}$ and immediately chilled on ice. The samples were then electrophoresed using an ABI 310 Genetic Analyzer. The amplified DNA fragments were analyzed by GeneScan software.

\section{Ratio of homozygosity}

To assess the statistical significance of associations, the percentage of homozygotes in patients versus that in unaffected relatives in consanguineous families was compared using standard $\chi$-squared formulas, along with the Yates correction if the size of any of the expected classes was fewer than five samples.

Linkage disequilibrium analysis

Differences in the overall distribution of alleles on diseasebearing and normal chromosomes were tested by standard $\chi$-squared formulas, along with the Yates correction if the size of any of the expected classes was fewer than five samples.

Allele counting prior to the linkage disequilibrium analysis was performed as follows:

In affected offspring of consanguineous marriages, if the marker genotypes were homozygous, only a single marker allele was counted in determining the marker allele frequency on the disease chromosomes. For individuals from nonconsanguineous marriages, or for individuals from consanguineous marriages where the marker locus was heterozygous, both marker alleles were counted.

\section{Haplotype analysis}

Haplotype analysis was performed with the markers D9S1878, D9S1817, D9S2177, D9S2178, D9S2179, D9S2180, D9S2181, D9S1804, D9S1791, D9S1859, and D9S1874, in the order suggested by the human genome sequence database of the Sanger Centre (http:// www.sanger.ac.uk/HGP/Chr9/). The haplotypes for the disease-bearing chromosomes, as well as those for healthy chromosomes, were derived from inspection of the family data. The most-likely haplotypes were constructed manually using the minimum recombination strategy. The phase of the $N M$ region was determined by genotyping the patients and their parents. When parents were not available, haplotypes were inferred from children.

\section{Results}

Excess of homozygosity

In autosomal recessive disorders, affected individuals from consanguineous families would be expected to be homozy-

Table 1. New markers used in this study

\begin{tabular}{|c|c|c|c|c|}
\hline Locus & $\begin{array}{l}\text { Primer sequences }{ }^{\mathrm{a}} \\
\left(5^{\prime}-3^{\prime}\right)\end{array}$ & $\begin{array}{l}\text { Product size } \\
\text { (bp) }\end{array}$ & Repeat & Heterozygosity \\
\hline D9S2177 & $\begin{array}{l}\text { GCCTTGAGTGTAAATGCCAA } \\
\text { GGGCACTGAGTGAAAAGAA }\end{array}$ & 200 & $(\mathrm{CTTT})_{16}$ & 0.82 \\
\hline D9S2178 & $\begin{array}{l}\text { CTCAAACTCCTGGCCTCAAG } \\
\text { CCATCACCATCATTAAGGCA }\end{array}$ & 148 & $(\mathrm{CA})_{26}$ & 0.93 \\
\hline D9S2179 & $\begin{array}{l}\text { CTCACTCCCTTCGTGGTCAT } \\
\text { CTCCAGGCAGATAGACAGCC }\end{array}$ & 200 & $(\mathrm{GTCT})_{13}$ & 0.68 \\
\hline D9S2180 & $\begin{array}{l}\text { CAGCTAGGGACTTGGAAGGA } \\
\text { TATCGACCCAGCCTCTCATT }\end{array}$ & 173 & $(\mathrm{AG})_{18}(\mathrm{TG})_{22}(\mathrm{GA})_{6}$ & 0.8 \\
\hline D9S2181 & $\begin{array}{l}\text { CTTGTTCAAAGGGGTTGGTC } \\
\text { TCTGATCСTCTAGCCCATGC }\end{array}$ & 160 & $(\mathrm{GT})_{21}$ & 0.52 \\
\hline
\end{tabular}

${ }^{a} 58^{\circ} \mathrm{C}$ annealing temperature was used in all polymerase chain reactions 
gous for an allele at the disease locus because of identity by descent from a common progenitor. We analyzed excess of homozygosity in the patients having NM using 18 microsatellite markers, which cover a region of $15 \mathrm{cM}$ on chromosome 9p1.

Eight of 18 polymorphic markers showed significant excess of homozygosity in consanguineous patients (Table 2). The patient in family 4 was heterozygous at D9S2178, and those in families 3 and 7 were heterozygous at D9S1874. All of the NM patients from consanguineous families were homozygous within the region between markers D9S2179 and D9S1859. One NM patient from a nonconsanguineous family was also homozygous in the region between markers D9S2179 and D9S1804.

Table 2. Homozygosity for 13 markers in the $N M$ region

\begin{tabular}{|c|c|c|c|c|c|c|}
\hline \multirow[b]{3}{*}{ Locus $^{\mathrm{a}}$} & \multicolumn{4}{|c|}{ Homozygosity } & \multirow[b]{3}{*}{$\chi^{2}$} & \multirow[b]{3}{*}{$P$} \\
\hline & \multicolumn{2}{|c|}{ Patients } & \multicolumn{2}{|c|}{ Relatives } & & \\
\hline & No. & $\%$ & No. & $\%$ & & \\
\hline D9S1845 & 7 & 87.5 & 0 & 0 & 12.5 & $<0.01$ \\
\hline D9S1878 & 7 & 87.5 & 1 & 8.3 & 9.5 & $<0.01$ \\
\hline D9S1817 & 7 & 87.5 & 4 & 33.3 & 3.7 & NS \\
\hline D9S2177 & 7 & 87.5 & 1 & 8.3 & 9.5 & $<0.01$ \\
\hline D9S2178 & 7 & 87.5 & 2 & 16.7 & 7.1 & $<0.01$ \\
\hline D9S2179 & 8 & 100.0 & 5 & 41.7 & 4.8 & $<0.05$ \\
\hline D9S2180 & 8 & 100.0 & 0 & 0.0 & 16.1 & $<0.01$ \\
\hline D9S2181 & 8 & 100.0 & 6 & 50.0 & 3.6 & NS \\
\hline D9S1804 & 8 & 100.0 & 6 & 50.0 & 3.6 & NS \\
\hline D9S1791 & 8 & 100.0 & 1 & 8.3 & 12.8 & $<0.01$ \\
\hline D9S1859 & 8 & 100.0 & 5 & 41.7 & 6.3 & $<0.05$ \\
\hline D9S1874 & 6 & 75.0 & 3 & 25.0 & 1.9 & NS \\
\hline D9S1862 & 2 & 28.6 & 2 & 22.2 & 0.1 & NS \\
\hline
\end{tabular}

NS, not significant

${ }^{a}$ The order of marker loci is based on previously published data (Dib et al. 1996; http://webace.sanger.ac.uk/)
Linkage disequilibrium analysis

Allele distributions for 18 polymorphic markers were compared with estimated frequencies for both the patients and their parents. Allele "199-bp" of D9S2179 was overrepresented on $N M$ chromosomes, although there were 7 alleles observed at this locus and this particular allele occurred in only $4.5 \%$ of Japanese control chromosomes (Table 3). When alleles on $N M$ chromosomes were compared with those on the healthy chromosomes of the parents, a significant linkage disequilibrium was detected in $199 \mathrm{bp}$ at this locus $\left(\chi^{2}=9.0 ; P<0.005\right)$. For D9S1859, the "107-bp" allele was overrepresented $\left(\chi^{2}=7.8 ; P<0.01\right)$, despite being the second most common allele in the control population (21.4\% in Japanese). Other alleles significantly associated with $N M$ chromosomes are shown in Table 4.

Five of six marker loci between markers D9S2179 and D9S1859 were exclusively associated with NM chromosomes, suggesting that markers D9S2178 and D9S1804 flank the polymorphism on the distal and proximal sides of the $N M$ region, respectively.

\section{Haplotype analysis}

The haplotypes of the $N M$ chromosomes are shown in Table 5. One predominant haplotype was present on affected chromosomes and was comprised of the alleles significantly associated with $N M$. The core haplotype, 199-160-154-109-178-107 (marker order: D9S2179D9S2180-D9S2181-D9S1804-D9S1791-D9S1859), was present on $50.0 \%$ of the affected chromosomes and on $0.0 \%$ of parent chromosomes, and was exclusively associated with $N M$ chromosomes $\left(\chi^{2}=9.3 ; P<0.005\right)$.

Two chromosomes had the haplotypes 199-160-154-109180-107 and 199-160-154-109-176-107, both of which could be derived from the core haplotype as a result of historical

Table 3. Allele sizes and frequencies of three new markers associated with the $N M$ region

\begin{tabular}{|c|c|c|c|c|c|}
\hline \multicolumn{2}{|l|}{ D9S2179 } & \multicolumn{2}{|l|}{ D9S2180 } & \multicolumn{2}{|l|}{ D9S2181 } \\
\hline Allele size $(b p)^{a}$ & Frequency $^{\mathrm{b}}$ & Allele size $(b p)^{a}$ & Frequency $^{\mathrm{b}}$ & Allele size (bp) & Frequency $^{\mathrm{b}}$ \\
\hline $\begin{array}{l}191 \\
199 \\
203 \\
207 \\
211 \\
215 \\
218\end{array}$ & $\begin{array}{l}0.034 \\
0.045 \\
0.56 \\
0.10 \\
0.10 \\
0.11 \\
0.045\end{array}$ & $\begin{array}{l}153 \\
155 \\
157 \\
160 \\
162 \\
164 \\
166 \\
168 \\
174 \\
176 \\
178 \\
181 \\
183 \\
185 \\
189 \\
194\end{array}$ & $\begin{array}{l}0.068 \\
0.034 \\
0.39 \\
0.080 \\
0.068 \\
0.045 \\
0.080 \\
0.023 \\
0.023 \\
0.011 \\
0.023 \\
0.011 \\
0.023 \\
0.045 \\
0.057 \\
0.023\end{array}$ & $\begin{array}{l}150 \\
152 \\
154 \\
158 \\
160 \\
162\end{array}$ & $\begin{array}{l}0.023 \\
0.15 \\
0.22 \\
0.49 \\
0.080 \\
0.045\end{array}$ \\
\hline
\end{tabular}

\footnotetext{
${ }^{\mathrm{a}}$ Each number shows the fragment size of the polymerase chain reaction (PCR) product

${ }^{b}$ Estimated from 88 chromosomes from Japan
} 
recombinational events, placing the $N M$ gene centromeric to marker D9S1791. Five historical recombinations were found between the $N M$ region and marker locus D9S2178, a marker on the immediate telomeric side of the core haplotype. Therefore, D9S2178 defined the telomeric boundary of the $N M$ region.

The results demonstrated that 8 of $11(72.7 \%) \mathrm{NM}$ families, including both consanguineous and nonconsanguineous marriages, carried the haplotype 199-160-154109 . This haplotype was exclusively associated with $\mathrm{NM}\left(\chi^{2}\right.$ $=12.6 ; P<0.001)($ Table 6$)$. These eight families originated from different geographic areas of Japan. The presence of a core haplotype, 199-160-154-109, may suggest the existence of a common progenitor in Japan.

\section{Discussion}

The basic molecular defects resulting in NM are still elusive. In our previous study (Ikeuchi et al. 1997), the $N M$ gene was localized to a 23.3-cM region defined distally by marker D9S319 and proximally by marker D9S276, based on link-

Table 4. Summary of allelic association data

\begin{tabular}{|c|c|c|c|c|c|}
\hline \multirow[b]{2}{*}{ Locus } & \multirow[b]{2}{*}{ Allele $^{a}$} & \multicolumn{2}{|c|}{ No. of chromosomes } & \multirow[b]{2}{*}{$\chi^{2}$} & \multirow[b]{2}{*}{$P$} \\
\hline & & Patients & Relatives & & \\
\hline D9S1878 & 289 & 11 & 1 & 7.4 & 0.0066 \\
\hline D9S1817 & 264 & 9 & 6 & 0.2 & 0.63 \\
\hline D9S2177 & 168 & 10 & 6 & 0.3 & 0.61 \\
\hline D9S2178 & 153 & 8 & 4 & 0.3 & 0.54 \\
\hline D9S2179 & 199 & 13 & 1 & 8.9 & 0.0028 \\
\hline D9S2180 & 160 & 13 & 2 & 7.2 & 0.0072 \\
\hline D9S2181 & 154 & 15 & 5 & 4.4 & 0.037 \\
\hline D9S1804 & 109 & 17 & 11 & 1.1 & 0.29 \\
\hline D9S1791 & 178 & 11 & 3 & 4.0 & 0.045 \\
\hline D9S1859 & 107 & 15 & 4 & 7.8 & 0.0051 \\
\hline D9S1874 & 198 & 11 & 4 & 1.9 & 0.17 \\
\hline
\end{tabular}

${ }^{a}$ Each number shows the fragment size of the PCR product age analysis. This is, however, too large a region to use when attempting to clone the gene using a positional cloning strategy. In this study, we have pursued an alternative strategy based on homozygosity and linkage disequilibrium analysis.

Homozygosity mapping is a powerful technique with which to map the genes responsible for recessive diseases (Lander and Botstein 1987). This strategy has typically been applied to diseases in consanguineous pedigrees (Pollak et al. 1993; Scheffield et al. 1994; Hillaire et al. 1994). In this study, we managed to apply homozygosity mapping to narrow the $N M$ region to approximately $3 \mathrm{cM}$ on chromosome 9p13 because three patients from three different consanguineous families happened to have informative recombinations on $N M$ chromosomes. The positional cloning strategy including homozygosity mapping is indeed powerful, but is often hampered by lack of informative recombinations. A larger number of consanguineous families would be required to narrow the $N M$ region more precisely by homozygosity mapping.

Linkage disequilibrium mapping is also a powerful tool for localizing the disease gene for Mendelian disorders that are relatively rare in the population, especially in studies such as this one, which use a limited number of families. (Farrall et al. 1987; Kerem et al. 1989; Huntington's Disease Collaborative Research Group 1993). In an ideal situation, most disease chromosomes descend from a single ancestral mutation, and the mutation is old enough for recombinations to have made the region of strongest linkage disequilibrium small (Kolehmainen et al. 1997). In this study, significant linkage disequilibrium was detected between the $N M$ region and several marker loci. The findings support the hypothesis that a major contribution was made from one founding $N M$ mutation in Japan. Furthermore, the observed large genetic region $(2.8 \mathrm{Mb})$ involved in significant linkage disequilibrium may suggest that the number of generations since the mutation occurred is small (Hoglund et al. 1995).

Haplotype analysis by a historical recombinational event is also useful for fine-mapping the location of the offending

Table 5. Multilocus haplotypes for polymorphic markers near the $N M$ gene in 11 patients

\begin{tabular}{|c|c|c|c|c|c|c|c|c|c|c|c|c|c|c|c|c|c|c|c|c|c|c|}
\hline \multirow[b]{3}{*}{ Locus } & \multicolumn{22}{|c|}{ Haplotypes in patients } \\
\hline & \multicolumn{12}{|c|}{ Consanguineous families } & \multicolumn{10}{|c|}{ Nonconsanguineous families } \\
\hline & $1-4$ & & $3-3$ & & $4-4$ & & $6-3$ & & $7-2$ & & $11-1$ & & $2-4$ & & $5-4$ & & $8-2$ & & $9-3$ & & $10-4$ & \\
\hline D9S1878 & 289 & 289 & 289 & 289 & 270 & 287 & 289 & 289 & 289 & 289 & 292 & 292 & 272 & 285 & 270 & 289 & 289 & 289 & 270 & 287 & 270 & 289 \\
\hline D9S1817 & 264 & 264 & 264 & 264 & 264 & 268 & 270 & 270 & 270 & 270 & 263 & 263 & 244 & 264 & 264 & 270 & 270 & 270 & 266 & 266 & 264 & 270 \\
\hline D9S2177 & 168 & 168 & 217 & 217 & 168 & 209 & 200 & 200 & 200 & 200 & 209 & 209 & 200 & 172 & 168 & 168 & 197 & 197 & 168 & 172 & 168 & 205 \\
\hline D9S2178 & 153 & 153 & 126 & 126 & 126 & 151 & 165 & 165 & 165 & 165 & 128 & 128 & 165 & 155 & 153 & 153 & 165 & 165 & 153 & 151 & 153 & 140 \\
\hline D9S2179 & 199 & 199 & 215 & 215 & 203 & 203 & \begin{tabular}{|l|}
199 \\
\end{tabular} & 199 & 199 & \begin{tabular}{|l|}
199 \\
\end{tabular} & 219 & 219 & \begin{tabular}{|l|}
199 \\
\end{tabular} & 203 & 199 & 203 & \begin{tabular}{|l|}
199 \\
\end{tabular} & 199 & 199 & 203 & 199 & 215 \\
\hline D9S2180 & 160 & 160 & 183 & 183 & 153 & 153 & 160 & 160 & 160 & 160 & 157 & 157 & 160 & 157 & 160 & 157 & 160 & 160 & 160 & 157 & 160 & 185 \\
\hline D9S2181 & 154 & 154 & 158 & 158 & 158 & 158 & 154 & 154 & 154 & 154 & 152 & 152 & 154 & 154 & 154 & 158 & 154 & 154 & 154 & 158 & 154 & 154 \\
\hline D9S1804 & 109 & 109 & 109 & 109 & .119....... & ........... & 109 & 109 & 109 & 109 & 111 & 111 & 109 & 109 & 109 & 109 & 109 & 109 & 109 & 109 & 109 & 109 \\
\hline D9S1791 & 178 & 178 & 184 & 184 & 178 & 178 & 178 & 178 & 178 & 178 & 174 & 174 & 178 & 186 & 178 & 162 & 178 & 180 & 176 & 182 & 178 & 182 \\
\hline D9S1859 & 107 & 107 & 109 & 109 & 107 & 107 & 107 & 107 & 107 & 107 & 109 & 109 & \begin{tabular}{|l}
107 \\
\end{tabular} & 109 & 107 & 109 & 107 & 107 & 107 & 107 & 107 & 109 \\
\hline D9S1874 & 198 & 198 & 198 & 206 & 198. & .198...... & 198 & 198 & 192 & 194 & 194 & 194 & 200 & 202 & 192 & 198 & 198 & 198 & 204 & 206 & 198 & 194 \\
\hline
\end{tabular}

The boxes indicate chromosomal regions associated with $N M$

Each haplotype is described by the fragment size of the PCR product 
Table 6. Haplotypes associated with $N M$ and normal chromosomes

\begin{tabular}{lcc}
\hline & \multicolumn{2}{c}{ No. of Chromosomes } \\
\cline { 2 - 3 } Haplotypes $^{\mathrm{a}}$ & $\mathrm{NM}$ & Healthy \\
\hline D9S2179-D9S2180-D9S2181-D9S1804 & 12 & 0 \\
199-160-154-109 & 2 & 2 \\
$203-157-158-109$ & 1 & 0 \\
$203-157-154-109$ & 1 & 0 \\
$203-157-152-111$ & 1 & 0 \\
$215-183-158-119$ & 1 & 0 \\
$215-185-154-109$ & 1 & 0 \\
$219-157-152-111$ & 1 & 0 \\
Others & 0 & 15 \\
Total & 20 & 17 \\
\hline
\end{tabular}

${ }^{a}$ Each number shows the fragment size of the PCR product

gene (Toda et al. 1996; Wang et al. 1997; Kolehmainen et al. 1997). In this study, one predominant haplotype (199-160154-109-178-107) composed of six significantly associated alleles was found on $50.0 \%$ of the $N M$ chromosomes. This haplotype was exclusively associated with the $N M$ chromosome and is likely to represent the ancestral haplotype in Japan. The historical recombination events were detected just distal to D9S2179 and just proximal to D9S1804, suggesting that the $N M$ gene lies between marker loci D9S2181 and D9S1791.

Interestingly, the haplotype 178-107-198 for markers D9S1791, D9S1859, and D9S1874 was found in patient 4-4 (Table 5). If that haplotype was part of the ancestral mutation, the $N M$ gene would be assigned to the region between the markers D9S1804 and D9S1791. The clinical course of the patient (described in Subjects and methods), however, differed slightly from those of other patients with the ancestral haplotype. Based on our entire set of data, we feel confident concluding that $N M$ lies between marker loci D9S2178 and D9S1791 (Fig. 1).

Mitrani-Rosenbaum and Argov et al. (1996) showed that the gene for hereditary inclusion body myopathy in Persian Jews is localized proximal to marker D9S165, and recent extended work confirmed that the hIBM gene is located in an approximately 1-Mb region between D9S1791 and D9S50 (Eisenberg et al. 1999). That region is just proximal to that of $N M$ as defined in this study, and there is no overlapped interval. One problem is that the order of markers is based on the draft sequence data of the human chromosome. We have completed the construction of a bacterial artificial chromosome (BAC) contig, which covers the $N M$ region defined in this study. A physical map of the region between D9S2178 and D9S50 will disclose whether the disorders NM and HIBM result from allelic mutation of the same gene.

In conclusion, the homozygosity and linkage disequilibrium mapping applied in this study refined the localization of the $N M$ gene to be the $1.5-\mathrm{Mb}$ region between D9S2178 and D9S1791. Linkage disequilibrium analysis also supported the hypothesis that a major contribution is made from one founding $N M$ mutation in Japan. We have already completed a BAC contig that covers the region of interest. Newly established polymorphic markers such as a single-

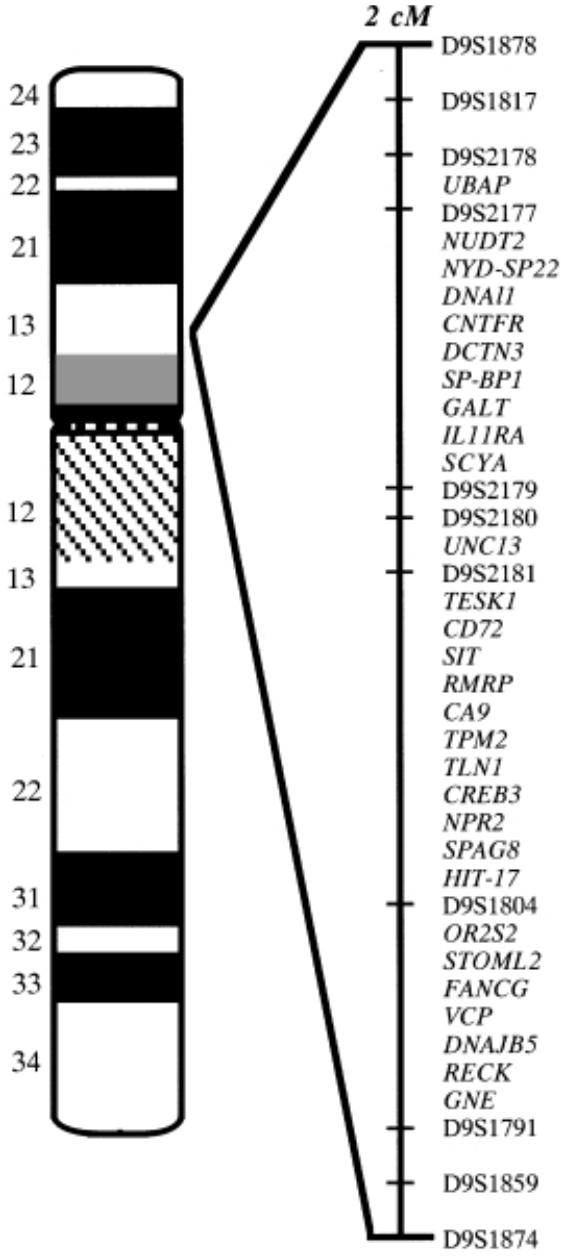

NM region

Fig. 1. Genetic and transcription map of the chromosome 9p13 region, showing the location of the $N M$ gene Oistances are based on previously published data (Dib et al. 1996; http://webace.sanger.ac.uk/)

nucleotide polymorphism will facilitate the refinement of the localization of the $N M$ locus and make possible a positional cloning strategy to clone the $N M$ gene.

Acknowledgments We are grateful to Dr. Sean Humphray of The Sanger Centre and Dr. Conover Talbot, Jr., of the Johns Hopkins School of Medicine for support given to our study.

\section{References}

Ahlberg G, Borg K, Ansved T, Edstrom L, Anvret M (1998a) Welander distal myopathy: genetic linkage and candidate genes on chromosome 2p. Muscle Nerve Suppl 7:S6

Ahlberg G, Borg K, Edstrom L, Anvert M (1998b) Welander hereditary distal myopathy: a molecular genetic comparison to hereditary myopathies with inclusion bodies. Neuromuscul Disord 8:111-114

Argov Z, Yarom R (1984) "Rimmed vacuole myopathy" sparing the quadriceps: a unique disorder in Iranian Jews. J Neurol Sci 64: $33-43$

Argov Z, Tiram E, Eisenberg I, Sadeh M, Seidman CE, Seidman JG, Karpati G, Mitrani-Rosenbaum S (1997) Various types of hereditary inclusion body myopathy map to chromosome 9p1-q1. Ann Neurol 41:548-551

Askanas V (1997) New development in hereditary inclusion body myopathy. Ann Neurol 41:421-422 
Askanas V, Engel WK (1995) New advances in the understanding of sporadic inclusion-body myositis and hereditary inclusion-body myopathies. Curr Opin Rheumatol 7:486-496

Askanas V, Engel WK (1998) Sporadic inclusion-body myositis and hereditary inclusion-body myopathies: current concepts of diagnosis and pathogenesis. Curr Opin Rheumatol 10:530-542

Barohn RJ, Amato AA, Griggs RC (1998) Overview of distal myopathies: from the clinical to the molecular. Neuromuscul Disord 8: 309-316

Dib C, Faure S, Fizames C, Samson D, Drouot N, Vignal A, Millasseau P, Marc S, Hazan J, Seboun E, Lathrop M, Gyapay G, Morissette J, Weissenbach J (1996) A comprehensive genetic map of the human genome based on 5,264 microsatellites. Nature 380:152-154

Eisenberg I, Thiel C, Levi T, Tiram E, Argov Z, Sadeh M, Jackson CL, Thierfelder L, Mitrani-Rosenbaum S (1999) Fine-structure mapping of the hereditary inclusion body myopathy locus. Genomics 55: $43-48$

Farrall M, Estibill X, Williamson R (1987) Indirect cystic fibrosis carrier detection. Lancet 10:156-157

Haravuori H, Makela-Bengs P, Udd B, Partanen J, Pulkkinen L, Somer H, Peltonen L (1998) Assignment of the tibial muscular dystrophy locus to chromosome 2q31. Am J Hum Genet 62:620-626

Hillaire D, Leclerc A, Faure S, Topaloglu H, Chiannikukchai N, Guicheney P, Grinas L, Legos P, Philpot J, Evangelista T, Routon MC, Mayer M, Pellissier JF, Estournet B, Barois A, Hentati F, Feingold N, Beckmann JS, Dubowitz V, Tome FMS, Fardeau M (1994) Localization of merosin-negative congenital muscular dystrophy to chromosome $6 \mathrm{q} 2$ by homozygosity mapping. Hum Mol Genet 3:1657-1661

Hoglund P, Sistonen P, Norio R, Holmberg C, Dimberg A, Gustavson KH, de la Chapelle A, Kere J (1995) Fine mapping of the congenital chloride diarrhea gene by linkage disequilibrium. Am J Hum Genet 57:95-102

Huntington's Disease Collaborative Research Group (1993) A novel gene containing a trinucleotide repeat that is expanded and unstable on Huntington's disease chromosome. Cell 72:971-983

Ikeuchi K, Asaka T, Saito M, Tanaka H, Higuchi S, Tanaka K, Saida K, Uyama E, Mizusawa H, Fukuhara N, Nonaka I, Takamori M, Tsuji S (1997) Gene locus for autosomal recessive distal myopathy with rimmed vacuoles maps to chromosome 9. Ann Neurol 41: $432-437$

Illa I (2000) Distal myopathy. J Neurol 247:169-174

Kerem B, Rommens JM, Buchanan JA, Markiewicz D, Cox TK, Chakravarti A, Buchwald M, Tsui LC (1989) Identification of the cystic fibrosis gene: genetic analysis. Science 245:1073-1080

Kolehmainen J, Norio R, Kivitie-Kallio S, Tahvanainen E, de la Chapelle A, Lehesjoki AE (1997) Refined mapping of the Cohen syndrome gene by linkage disequilibrium. Eur J Hum Genet 5:206-213

Laing NG, Laing BA, Meredith C, Wilton SD, Robbins P, Honeyman K, Dorosz S, Kazman H, Mastaglia FL, Kakukas BA (1995) Autosomal dominant distal myopathy: linkage to chromosome 14 Am J Hum Genet 56:422-427

Lander ES, Botstein D (1987) Homozygosity mapping: a way to map human recessive traits with the DNA of inbred children. Science 236:1567-1570
Levy E, Carman MD, Fernandez-Madrid IJ, Power MD, Lieberburg I, van Duinen SG, Bots GT, Luyendijk W, Frangione B (1990) Mutation of the Alzheimer's disease amyloid gene in hereditary cerebral hemorrhage, Dutch type. Science 248:1124-1126

Matsubara S, Tanabe H (1982) Hereditary distal myopathy with filamentous inclusions. Acta Neurol Scand 65:363-368

Mitrani-Rosenbaum S, Argov Z, Blumenfeld A, Seidman CE, Seidman JG (1996) Hereditary inclusion body myopathy maps to chromosome 9p1-9q1. Hum Mol Genet 5:159-163

Mizusawa H, Kurisaki H, Takatsu M, Knoue K, Mannen T, Yoyokura Y, Nakanishi T (1987) Rimmed vacuolar distal myopathy: a clinical, electrophysiological, histopathological and computed tomographic study of seven cases. J Neurol 234:129-136

Mullan M, Crawford F, Axelman K, Houlden H, Lilius L, Winblad B, Lannfelt L (1992) A pathogenic mutation for probable Alzheimer's disease in the APP gene at the N-terminus of beta-amyloid. Nat Genet 1:345-347

Murakami N, Ihara Yasuo, Nonaka I (1995) Muscle fiber degeneration in distal myopathy with rimmed vacuole formation. Acta Neuropathol 89:29-34

Nonaka I (1999) Distal myopathies. Curr Opin Neurol 12:493-499

Nonaka I, Sunohara N, Ishiura S, Satoyoshi E (1981) Familial distal myopathy with rimmed vacuole and lamellar (myeloid) body formation. J Neurol Sci 51:141-145

Nonaka I, Sunohara N, Satoyoshi E, Terasawa K, Yonemoto K (1985) Autosomal recessive distal muscular dystrophy: a comparative study with distal myopathy with rimmed vacuole formation. Ann Neurol 17:51-59

Nonaka I, Murakami N, Suzuki Y, Kawai M (1998) Distal myopathy with rimmed vacuoles. Neuromuscul Disord 8:333-337

Pollak MR, Wu Chou YH, Cerda JJ, Steinmann B, La Du BN, Seidman JG, Seidman CE (1993) Homozygosity mapping of the gene for alkaptonuria to chromosome 3q2. Nat Genet 5:201-204

Sarkozi E, Askanas V, Johnson SA, Engel WK, Alvarez RB (1993) Beta-amyloid precursor protein mRNA is increased in inclusionbody myositis muscle. Neuroreport 4:815-818

Scheffield VC, Carmi R, Kwitek-Black A, Rokhlina T, Nishimura D, Duyk GM, Elbedour K, Sunden SL, Stone EM (1994) Identification of a Bardet-Biedl syndrome locus on chromosome 3 and evaluation of an efficient approach to homozygosity mapping. Hum Mol Genet 3:1331-1335

Sivakumar K, Cervenakova L, Dalakas MC, Leon-Monzon M, Issacson SH, Nagle JW, Vasconcelos O, Goldfarb LG (1995) Exons 16 and 17 of the amyloid precursor protein gene in familial inclusion body myopathy. Ann Neurol 38:267-269

Sunohara N, Nonaka I, Kamei N, Satoyoshi E (1989) Distal myopathy with rimmed vacuole formation: a follow-up study. Brain 112:65-83

Toda T, Miyake M, Kobayashi K, Mizuno K, Saito K, Osawa M, Nakamura Y, Kanazawa I, Nakagome Y, Tokunaga K, Nakahori Y (1996) Linkage-disequilibrium mapping narrows the Fukuyamatype congenital muscular dystrophy (FCMD) candidate region to $<100 \mathrm{~kb}$. Am J Hum Genet 59(6):1313-1320

Wang CY, Hawkins-Lee B, Ochoa B, Walker RD, She JX (1997) Homozygosity and linkage-disequilibrium mapping of the Urofacial (Ochoa) syndrome gene to a 1-cM interval on chromosome 10q23q24. Am J Hum Genet 60:1461-1467 